\title{
A ANÁLISE JURÍDICA DA POLÍTICA ECONÔMICA APLICADA AO PROGRAMA MINHA CASA, MINHA VIDA: UM ESTUDO DE CASO DE BRASÍLIA (2014-2017)
}

\author{
THE LEGAL ANALYSIS OF ECONOMIC POLICY APPLIED TO THE 'MINHA CASA, MINHA VIDA' \\ PROGRAM: A CASE STUDY OF BRASÍLIA (2014-2017)
}

\author{
Camilla Fernandes Moreira ${ }^{1}$ \\ Marcus Faro de Castro
}

\section{Resumo}

O Programa Minha Casa, Minha Vida (PMCMV) completa, em 2019, dez anos de execução e, embora seja reconhecidamente o maior programa habitacional já implementado no país, seu futuro é, atualmente, incerto. O histórico da atuação do poder público na solução de problemas relacionados à moradia, remonta, no país, programas sociais paliativos, pontuais, desarticulados e ineficazes. A análise realizada busca incorporar atributos muito mais amplos que o mero quantitativo de unidades produzidas por faixas de renda, realizando uma pesquisa empírica voltada também para a verificação de elementos outros, tais como localização e disponibilidade de modais de transporte, a existência de equipamentos sociais, a estrutura física e a dimensão dos imóveis e reflexos do contexto políticoeconômico. A metodologia da Análise Jurídica da Política Econômica (AJPE), empregada neste trabalho, tornou esse exame possível, tanto em termos de produção de um Índice de Fruição Empírica por Faixa

\footnotetext{
${ }^{1}$ Graduação em Direito (UFU), Mestre em Ciências Sociais (UFU) e Doutorado em Direito (UnB). Docente em cursos jurídicos e pesquisadora do GDES. Pesquisadora em temas relacionados a direitos humanos, análise jurídica da política econômica e políticas públicas. Universidade de Brasília - UNB - Brasil. ORCID iD: https://orcid.org/0000-0002-1875-7859 Lattes: http://lattes.cnpq.br/3043368714127373 $\quad$ E-mail: camillafernandesmoreira@yahoo.com.br

2 Professor Titular da Universidade de Brasília (departamento de Direito), atuando principalmente nos seguintes temas: globalização, direitos humanos, direito e política, política econômica e análise jurídica da política econômica (AJPE). Possui graduação em Direito pela Pontifícia Universidade Católica do Rio de Janeiro (1983), graduação em Letras Português Licenciatura pela Pontifícia Universidade Católica do Rio de Janeiro (1980), mestrado em Direito - Harvard University (1986) e doutorado em Direito - Harvard University (1990). Universidade de Brasília - UNB - Brasil. É autor de vários artigos publicados em periódicos nacionais e estrangeiros. É coorganizador do livro Análise Jurídica da Política Econômica: A Efetividade dos Direitos na Economia Global. ORCID iD: https://orcid.org/0000-0002-6487-1783 URL: https://economialegal.wordpress.com/_ Lattes: http://lattes.cnpq.br/8117165300109701. E-mail: mfarounb@gmail.com
} 
de Renda (Análise Posicional), como para fins de identificar alguns efeitos que indicadores macroeconômicos podem ter sobre a fruição desse mesmo direito à moradia. Os resultados são, infelizmente, desalentadores, há muitas distorções a serem enfrentadas pelo PMCMV, principalmente quanto à distribuição de imóveis por faixa de renda e a viabilidade de fruição do direito à moradia nas condições dispostas.

Palavras-chave: Programa Minha Casa Minha Vida; Direito à Moradia; Análise Jurídica da Política Econômica; Índice de Fruição Empírica; Análise Empírica; Brasília (DF).

Abstract: The Brazilian housing policy known as "Programa Minha Casa, Minha Vida" (PMCMV) (literally: "My Home, My Life Program") has been in existence for ten years since its inception in 2019. Although it is recognized as the largest housing program ever implemented in Brazil, its future is currently uncertain. The program initially addressed the needs of poor classes. However, policy implementation has led to the deepening of existing disparities with respect to the enjoyment of the right to housing by the most disadvantaged social groups. In addition to considering data regarding the number of housing units produced by income bracket of prospective home buyers, our analysis has covered elements that we take as being significantly associated to the enjoyment of the right to housing. Therefore, we looked at elements such as location and modalities of transportation available to the beneficiaries of the program, available social facilities, the physical structure and dimension of housing units and also impacts of the some variables of the political-economic context. The approach and methodology established by the Legal Analysis of the Economic Policy (LAEP) made this examination possible both in terms of producing an Index of Empirical Enjoyment referring to the housing right of home buyers belonging to different income brackets, and as a way of making a preliminary assessment of the effects that some macroeconomic indicators may have on the enjoyment of the right to housing of home buyers associated with the program. The results are, unfortunately, discouraging, there are many distortions to be faced by the PMCMV, especially regarding the distribution of real estate by income bracket and the possibility of enjoying the right to housing under the conditions provided.

Keywords: My Home, My Life Program; Right to Housing; Legal Analysis of the Economic Policy; Index of Empirical Enjoyment; Empirical Analyze; Brasília (DF) 
Introdução

A terceira conferência das Nações Unidas sobre assentamentos urbanos, conhecida por Habitat III, ocorreu em outubro de 2016 no Equador e reuniu prefeitos, representantes de autoridades locais, setores da sociedade civil, organizações urbanas e acadêmicos, entre outros. Do mesmo modo que nas conferências anteriores (Habitat I / 1978 - Canadá e Habitat II / 1996 - Turquia), após as rodadas de propostas e debates, foi confeccionado um documento com disposições sobre os pontos considerados mais relevantes de alteração do quadro habitacional para os próximos vinte anos. (UNITED NATIONS, 2016)

O documento designado por Nova Agenda Urbana (NAU) reflete termos negociados pelas 193 nações que compõem a Organização das Nações Unidas (ONU) e, apesar de não apresentar caráter legalmente vinculante para os Estados-membros ou prefeituras, serve como meio orientador para que os atores envolvidos no processo de desenvolvimento urbano construam seus planos de ação. Além disso, a carta visa estabelecer uma visão compartilhada de normas para a transformação de determinadas áreas urbanas, utilizando para isso estruturas de planejamento e desenvolvimento adequadas. (WRI BRASIL, 2016)

Meses antes da realização do evento foi produzido um rascunho da NAU com base em sugestões e negociações realizadas durante reuniões consultivas com os Estados-membros. Além desse rascunho, outros 10 documentos sobre políticas habitacionais e urbanas foram confeccionados por um grupo de especialistas. As produções constituem uma importante fonte técnica para implementação de políticas urbanas nos diferentes níveis de governo, quais sejam, a sociedade civil, o setor acadêmico, o setor privado etc. (UNITED NATIONS, 2016)

O documento específico sobre habitação e serviços básicos, produzido no âmbito da conferência Habitat III, traz importantes conceitos utilizados no presente trabalho, como base para a composição da habitação adequada. $O$ texto é claro ao enfatizar a noção de que "habitação adequada deve prover mais do que 4 paredes e um telhado". Além disso, há a exigência de que "[u]m número de condições [sejam] atingidas antes que formas específicas de abrigos possam ser considerados habitação adequada". (HABITAT III, 2015) 
Nesse sentido, alguns elementos constitutivos desse conceito merecem atenção: segurança de posse; disponibilidade de serviços, materiais, instalações e infraestrutura; acessibilidade financeira; habitabilidade e segurança física; acessibilidade; localização e adequação cultural. (HABITAT III, 2015)

O documento oficial publicado ao final do evento contém 175 tópicos e, após a assinatura da declaração, os Estados-membros da ONU comprometeram-se a utilizar os meios apropriados para efetivação dessas diretrizes. Podem ser identificados no texto cinco principais campos de orientação: A. política urbana nacional; B. legislação urbana; C. planejamento e projeto urbano; D. economia urbana e finanças municipais; E. extensões / renovações urbanas planejadas. (CONSELHO DE ARQUITETURA E URBANISMO, 2016)

Para construção do presente artigo, alguns tópicos de maior interesse expostos na NAU foram selecionados para análise empírica, tais como a estruturação da política urbana nacional e as formas de planejamento e projetos urbanos. Esses tópicos incluem aspectos que são relevantes para a efetividade do direito à moradia, mas que são por vezes ignorados.

Sobre a política urbana nacional, merecem destaque: o planejamento baseado nas projeções demográficas; o planejamento para regiões em vez de cidades apenas; uma política urbana nacional que faça a distinção entre a distribuição de responsabilidade para todos os níveis de governo; o planejamento urbano associado ao aspecto normativo proporcionado pela lei; e a garantia de padrões mínimos no planejamento de serviços urbanos básicos.

Quanto às disposições do documento produzido pela NAU referentes ao planejamento e projeto urbano, para fins de demonstração do método da Análise Jurídica da Política Econômica (AJPE), foram escolhidos os seguintes pontos concebidos como conteúdos da política de habitação: a) questões relativas ao tempo de viagem entre a casa; b) o fator humano, ou seja, os moradores devem estar no centro do planejamento urbano evitando assim a segregação entre grupos socioeconômicos; c) os serviços urbanos básicos e seu nível de acesso pelos moradores da área analisada, entre outros.

Apesar da abordagem bastante ampla e analítica adotada pela NAU, este documento foi alvo de críticas realizadas após sua divulgação. A Habitat International Coalition (HIC), movimento global constituído na primeira Conferência (Habitat I) que conta hoje com mais de 400 membros, reprovou alguns aspectos da carta sobre pautas abandonadas e/ou ausência de enfoque em determinadas questões. Um exemplo de ponto controverso explicitado pelo grupo é a privação de legislação protetiva contra despejos forçados e ausência de diretrizes no que diz respeito à realização progressiva do direito humano à moradia adequada. (Habitat International Coalition, 2016) 
(...) Em essência, a Habitat III reduziu o objetivo da Agenda o que também se reflete no título "Nova Agenda Urbana". Isso sem abordar causas estruturais de urbanização desequilibrada e habitação inadequada (...)Problemas críticos, tais como sistemas de alimentação entre cidades-regiões, agroecologia e direitos dos pequenos agricultores; o papel crucial da economia, da solidariedade social e da assistência; regulamentação dos mercados financeiros e habitacionais; captação de terras e proteção dos direitos territoriais das comunidades; e a necessidade de questionar o quadro macroeconômico atual e as políticas externas que promovem a violação dos direitos humanos, não foram adequadamente abordados. (Habitat International Coalition, 2016)

Além disso, o grupo demonstrou preocupação com a criminalização de movimentos sociais e participação popular, com a especulação imobiliária produzida pela falta de regulamentação de política urbana, as formas de financiamento habitacionais, os reflexos da política macroeconômica sobre o acesso à moradia adequada e os modelos possíveis de desenvolvimento urbano.

Ao encerrar o texto, foi destacada a necessidade de ampliação dos debates para atores importantes para o processo de construção das diretrizes "Ainda aspiramos a viver em estados de direitos humanos compostos de seus povos, territórios e instituições democráticas. Para perceber essa visão do habitat, nossas comunidades insistem: "nada sobre nós sem nós."” (Habitat International Coalition, 2016)

Adotando uma perspectiva crítica semelhante, a "Carta do Rio de Janeiro nos Bairros e no Mundo, em Luta pelo Direito à Cidade, pela Democracia e Justiça Urbanas oriunda do Fórum Social Urbano" (2010) ${ }^{3}$, também havia reprovado, alguns anos antes, o fato de os documentos internacionais não incorporarem análises concretas das causas da pobreza e da desigualdade e, no mesmo sentido, não se oporem aos mecanismos reprodutores da concentração de renda e poder.

Elaborada por movimentos populares, organizações da sociedade civil, instituições públicas, acadêmicas e profissionais, a referida carta traz à tona a utopia anticapitalista do direito à cidade, pondo em questão não apenas o acesso aos serviços e equipamentos urbanos básicos, mas, sobretudo, o direito a participar da construção de uma cidade que se contraponha à lógica mercantil, que organiza o espaço de acordo com seus interesses, de maneira a otimizar a extração da mais-valia urbana às custas da degeneração da sociabilidade nos espaços públicos, ao criar, entre outras estruturas, ambientes privados, enclaves e muros em nome da proteção e da privacidade. (IPEA, 2016)

\footnotetext{
${ }_{3}^{3}$ Carta resultante do Fórum Social Urbano - Organizado no Rio de Janeiro em 2010 que ocorreu paralelamente ao V Fórum Urbano Mundial, promovido pela ONU-Habitat.
} 
É importante, nesse momento, demonstrar como os administradores públicos no Brasil lidam com as diretrizes elaboradas e contidas nas cartas. Vale a pena repetir que o documento não é vinculante do ponto de vista jurídico e tampouco deveria ser. Portanto, não cria obrigação para cumprimento estrito pelos administradores públicos. Não obstante, diante da existência do documento, forma-se uma expectativa de comprometimento pelos formuladores de políticas públicas relativamente às pautas descritas nos ofícios.

\section{O Estatuto da Cidade}

Um ponto relevante para tópico trata da edição do Estatuto da Cidade, em 2001, que representou "no momento de sua criação, a pactuação do que seria uma Nova Agenda Urbana brasileira dos anos 2000, ao trazer um conjunto de ferramentas (instrumentos) que deveriam ser implementados nas cidades por meio da elaboração dos planos diretores". (IPEA, 2016a)

O Estatuto da Cidade reuniu diversos instrumentos como:

a) instrumentos de indução ao desenvolvimento urbano, como é o caso do parcelamento, edificação ou da utilização compulsório; do Imposto Predial e Territorial Urbano (IPTU) progressivo no tempo; da outorga onerosa do direito de construir; das operações urbanas consorciadas; do direito de preempção, entre outros.

b) instrumentos de regularização fundiária - tendo como bases legais para sua política - o direito à moradia e às cidades sustentáveis - como as zonas especiais de interesse social (ZEIS); o usucapião especial de imóvel urbano; e a concessão de uso especial para fins de moradia e direito real de uso.

c) instrumentos de democratização da gestão urbana, que visa atender às diretrizes constitucionais da democracia participativa e representativa.

Os planos diretores de caráter obrigatório para os municípios com mais de 20 mil habitantes, passaram a ser um importante instrumento de organização e planejamento urbano das cidades. Entretanto, há falhas no que se refere à aplicação eficaz desses mecanismos viabilizados pelo documento. As ZEIS, por exemplo, estão presentes em $81 \%$ dos planos diretores existentes no Brasil, mas um pequeno número de municípios realmente demarcou as áreas destinadas às zonas especiais e promoveu algum tipo produção de moradias para famílias de baixa renda. (IPEA, 2016)

Dessa forma, fica evidente a desconexão entre as previsões dos planos diretores e sua real aplicação na política urbana. Outro problema a ser enfrentado é a articulação entre os dispositivos do 
plano e o planejamento orçamentário que serve de base à sua execução. Além disso, a inserção e localização do município também são fatores que podem gerar dificuldades de implementação:

(...) grande parte dos municípios têm como obrigatória a elaboração do plano diretor está inserida em regiões metropolitanas, em aglomerações urbanas ou são cidades médias inseridas em lógicas regionais dinâmicas. Ao encerar as diretrizes nas fronteiras municipais, perde-se a contextualização de toda influência sofrida e exercida pelos municípios do entorno, tratando as grandes questões de maneira pontual e não sistêmica. (IPEA, 2016)

Através da conversão da medida provisória em Lei, em 2009, tem início a execução do Programa Minha Casa Minha Vida, de dimensões consideráveis no quesito quantitativo e com algumas deficiências do ponto de vista qualitativo. Com o principal objetivo de reduzir o déficit habitacional no país, o programa tornou-se uma importante fonte de avaliação de eficácia de políticas públicas, uma vez que recebeu aporte financeiro elevado e atingiu números significativos de produção de moradia em todo o País.

Em 2016, finalmente, o Brasil participou dos processos de debates e discussões prévias da Habitat III, seguindo inclusive a estrutura indicada pela ONU para a confecção do relatório nacional. O conteúdo apresentou a discussão sobre a metropolização e o direito à cidade, além de demonstrar avanços das políticas sociais, criação de espaços de participação, conselhos e recortes das políticas habitacionais especificamente para grupos mais vulneráveis. (IPEA, 2016)

É necessário reconhecer que a postura ativa dos formuladores de políticas públicas, evidenciada por meio da participação efetiva nos debates e pela produção de um relatório bastante detalhado e condizente com as expectativas em longo prazo, foi um sinal positivo. No entanto, esse avanço precisa ser lido num contexto mais amplo. Em parte, em razão do histórico supracitado de desarticulação, má utilização dos recursos, ausência de implementação das diretrizes e políticas inconsequentes. Noutra parte, em razão da mudança conjuntural da política brasileira, que gerou o atual cenário de vulnerabilidade para os programas sociais.

A análise adequada do quadro demonstrado no texto deve compreender desde a interconexão de aspectos múltiplos influentes, como as necessidades dos atores envolvidos (moradores, setores da construção civil, formuladores de políticas públicas, movimentos sociais) até a possibilidade de manejo e quantificação dos desempenhos de programas habitacionais. 
A proposta do presente artigo é justamente empregar um método avaliativo de políticas públicas que seja empiricamente referenciado. Análises que utilizam exclusivamente números relacionados ao déficit habitacional, ignorando fatores qualitativos relevantes para apreciação, não proporcionam contribuição adequada para o aperfeiçoamento dessas políticas.

A utilização da Análise Jurídica da Política Econômica para o estudo do PMCMV pode permitir a exposição dos pontos controversos do programa social de forma mais objetiva, bem como gerar uma maior expectativa de superação dos problemas relacionados ao setor. Em decorrência das circunstâncias expostas, a ferramenta de avaliação empírica empregada será a Análise Jurídica da Política Econômica.

Acerca das diretrizes de documentos internacionais e da incorporação destes ao sistema nacional por meio das políticas públicas, duas situações complexas foram evidenciadas até o momento.

Primeiramente, os documentos internacionais sofrem críticas por apresentarem um conteúdo insuficiente no que se refere a elementos componentes do direito à moradia e sua progressiva realização e a participação de todos os atores envolvidos, além de não integrarem análises concretas das causas da pobreza e da desigualdade.

A segunda situação complexa é referente à introdução desses dispositivos no sistema brasileiro. Afinal, o Estatuto da Cidade, promulgado em 2001, foi o principal documento elaborado até o momento e um dos seus pontos substanciais refere-se à criação dos planos diretores, indicação que foi prontamente seguida pela maioria dos municípios. Entretanto, conforme ressaltado anteriormente, esses documentos apresentam uma síndrome de ineficácia das regras no campo urbanístico revelando-se frágil frente à necessidade de alteração do atual quadro habitacional brasileiro.

2. A Análise Jurídica da Política Econômica (AJPE) e o Programa Minha Casa, Minha Vida (PMCMV)

\section{$2.1 \quad$ A AJPE}

A Análise Jurídica da Política Econômica (AJPE) é um conjunto de concepções e procedimentos de análise jurídica alternativos aos conceitos e análises próprios à dogmática jurídica comumente praticada no Brasil. Trata-se de uma alternativa que pode contribuir sobremaneira para a superação 
dos pontos críticos anteriormente mencionados. A AJPE apresenta-se sob uma perspectiva que utiliza a apresentação de dados de forma a dar precisão a uma realidade empírica, abrangendo assim a análise da real fruição de direitos por seus sujeitos. Conforme expõe Castro (2014, p. 44), "a visão da AJPE focaliza especialmente a fruição dos direitos, termo que se refere ao gozo de direitos enquanto experiência social que ocorre em um contexto específico". Uma das estratégias metodológicas propostas pela AJPE consiste na "Análise Posicional". Sua aplicação a fatos relevantes pode auxiliar na identificação de deficiências nas políticas públicas relacionadas ao setor habitacional, com impacto sobre a efetividade do direito à moradia de titularidade dos participantes do Programa.

O primeiro passo da Análise Posicional refere-se à identificação da política pública ou econômica e sua correlação com a representação jurídica de um ou mais direitos subjetivos (CASTRO, 2018, p. 128), que, no caso abordado, se expressam no PMCMV e no "direito à moradia" ${ }^{4}$ dos membros do Programa.

Essa conexão (entre a política pública o direito subjetivo) no presente caso é evidenciada pelo objetivo do PMCMV, a saber, a produção de moradias para diferentes grupos sociais previamente definidos pelas "Faixas de Renda" determinadas pelo Programa. O direito à moradia passou a constar como direito social após a aprovação da E.C. № 26 de 14 de fevereiro de 2000, ${ }^{5}$ exigindo a partir de então, a confecção de políticas públicas para sua eficácia. As Faixas de Renda consideradas pelo Programa, constantes da Lei 11.977/2009 são as seguintes:

Tabela 1 - Faixas do PMCMV

\begin{tabular}{cc}
\hline $\begin{array}{c}\text { Faixas de Renda do } \\
\text { programa }\end{array}$ & Renda \\
\hline Faixa 1 & até $R \$ 1,8$ mil \\
Faixa 2 & até $R \$ 4$ mil \\
Faixa 3 & até $R \$ 9$ mil \\
\hline
\end{tabular}

\footnotetext{
${ }^{4}$ art. 60 da Constituição Federal

${ }^{5} \mathrm{O}$ teor da E.C. no 26 é o seguinte: "Art. 10 0 art. 6o da Constituição Federal passa a vigorar com a seguinte redação: 'Art. 60: São direitos sociais a educação, a saúde, o trabalho, a moradia, o lazer, a segurança, a previdência social, a proteção à maternidade e à infância, a assistência aos desamparados, na forma desta Constituição.'"

${ }^{6}$ Além das três faixas de renda indicadas, foi criada a "Faixa 1,5" correspondente à renda de $\mathrm{R} \$ \mathbf{2 , 6}$ mil. Contudo, essa faixa não considerada na pesquisa deste trabalho, uma vez que, no intervalo do recorte temporal estabelecido (2014-2017), não estavam disponíveis dados oficiais consolidados sobre imóveis construídos para esse grupo em Brasília-DF.
} 


\section{Fonte: Caixa Econômica Federal (2017)}

O segundo passo da análise posicional prevê a "decomposição analítica" do conteúdo relacional dos direitos subjetivos. O conteúdo relacional dos direitos subjetivos pode ser obtido a partir da indicação de quais padrões de ação institucional e comportamento social serão considerados necessários para a efetiva fruição de um direito. ${ }^{7}$ Deve-se partir do pressuposto de que tais componentes relacionais em conjunto "dão conteúdo ao fato empírico da fruição do direito em questão" (CASTRO, 2018, p. 128)

Para o caso selecionado, o direito à moradia será decomposto em elementos considerados essenciais para sua adequada eficácia, quais sejam: (i) a produção de unidades habitacionais e sua relação com o déficit em cada "Faixa de Renda" do Programa; (ii) a disponibilidade de modais de mobilidade, incluindo serviços de transporte urbano, nos locais dos empreendimentos; (iii) os equipamentos sociais disponíveis; e por fim, (iv) a estrutura ${ }^{8}$ dos imóveis. A opção pelos elementos supramencionados é realizada após a identificação destes por meio de trabalhos empíricos realizados na pós-ocupação ${ }^{9}$ com os beneficiários e algumas fontes internacionais. ${ }^{10}$

Em relação ao primeiro elemento, sua justificativa merece ser exposta de forma mais detalhada. Alguns dados demonstram que o público-alvo da Faixa 1 não tem sido atendido de forma proporcional à sua necessidade. Levando isto em conta, a pesquisa realizou uma análise de fruição

\footnotetext{
7 Os "conteúdos relacionais" (ou "elementos relacionais") correspondem a "padrões de ação institucional ou comportamento social (...) considerados necessários para a efetiva fruição de um direito [subjetivo]" (CASTRO, 2018, p. 31).

${ }^{8}$ Tamanho de cada unidade habitacional $\left(\mathrm{em}^{2}\right.$ ) x número de moradores.

${ }^{9}$ O Trabalho Técnico Social está previsto no Artigo 6ㅇ da Portaria Interministerial CGU/MF/MP 507/2011 e representa o conjunto de ações que visa promover a autonomia e o protagonismo social. São ações planejadas para criar mecanismos capazes de viabilizar a participação dos beneficiários nos processos de decisão, implantação e manutenção dos bens/serviços, adequando-os às necessidades e à realidade dos grupos sociais atendidos, além de incentivar a gestão participativa para a sustentabilidade do empreendimento. As diretrizes para elaboração e implantação do TTS são definidas pelo Ministério das Cidades, cabendo à Caixa Econômica Federal apoiar os entes públicos na formulação dos projetos e acompanhar e atestar sua execução. Um dos principais documentos produzidos através do Trabalho Técnico Social é a Avaliação de pós-ocupação que visa identificar os pontos positivos e pontos negativos da política pública implementada através de questionários e entrevistas aplicados diretamente aos beneficiários do Programa.

${ }^{10}$ Vale destacar que a AJPE estimula a análise de documentos internacionais referentes ao objeto em foco para contribuir com a determinação dos elementos a serem considerados relevantes para a fruição do direito. Um bom exemplo consiste no Comentário Geral no 4 do Comitê de Direitos Econômicos, Sociais e Culturais da Organização das Nações Unidas exprime orientações importantes sobre as disposições do Pacto Internacional sobre os Direitos Econômicos, Sociais e Culturais que em seu art. 11으 reconhece o direito à moradia adequada. (UNITED NATIONS, 1991)
} 
empírica específica para cada Faixa do PMCMV visando demonstrar possíveis variações de resultado conforme cada grupo de público-alvo.

Além disso, os investimentos direcionados às Faixas 2 e 3 apresentam o mercado como agente determinante na escolha da localização das construções. São construídos conjuntos habitacionais modernos e providos de infraestrutura mínima em localizações bastante razoáveis, atendidas por modais de mobilidade e complementadas com os instrumentos e equipamentos sociais e urbanos necessários à habitação com qualidade. Por outro lado, as habitações destinadas à Faixa 1 ficam à mercê dos planos diretores das cidades e das suas zonas especiais de interesse social. Se estiverem à margem do perímetro urbano, com dificuldade de acesso e sem equipamentos urbanos necessários, isso não impede, infelizmente, a destinação dos terrenos a essa produção. $O$ que se observa quando empreendimentos destinados à Faixa 1 são construídos em áreas distantes do meio urbano, é o objetivo de valorização dos terrenos contíguos ${ }^{11}$ - entre as habitações para a Faixa 1 e o núcleo da cidade. Posteriormente essas mesmas áreas, agora valorizadas, serão destinadas às Faixas 2 e 3.

Após essa contextualização, é possível tratar da terceira etapa da Análise Posicional, na qual é realizada a mensuração de aspectos da fruição de direitos para uma dada situação empírica. Com os elementos supra destacados, torna-se possível a determinação de um índice quantitativo de fruição empírica (IFE) do direito à moradia, a partir da decomposição dos índices referentes às respectivas Faixas de Renda do PMCMV:

$$
\begin{aligned}
& M F_{1}=\frac{\left(Q_{1}-D_{1}\right)+(T+I+E) 4}{} \\
& M F_{2}=\frac{\left(Q_{2}-D_{2}\right)+(T+I+E) 4}{}
\end{aligned}
$$

\footnotetext{
${ }^{11}$ MOREIRA (2013, p. 106)
} 


$$
M F_{3}=\underline{\left(Q_{3}-D_{3}\right)+(T+I+E) 4}
$$

Nas equações 1, 2 e 3 acima, $M F_{1}$ corresponde ao índice de fruição empírica (IFE) do direito à moradia de beneficiários do PMCMV classificados na Faixa 1 de renda. $M F_{2}$ e $M F_{3}$, aos classificados nas Faixas 2 e 3 , respectivamente. $Q_{1}$, representa a quantidade das habitações construídas para os pleiteantes classificados na Faixa 1 de renda e $Q_{2}$ e $Q_{3}$, aos classificados nas Faixas 2 e 3, respectivamente. $D_{1}, D_{2}$ e $D_{3}$ referem-se aos déficits habitacionais que se apresentam relativamente aos beneficiários das Faixas 1, 2 e 3, respectivamente.

Além disso, a variável $T$ refere-se à disponibilidade de modais de mobilidade/transporte nas áreas urbanas escolhidas para os empreendimentos; I, à infraestrutura básica disponível; e por fim, $E$, à estrutura dos imóveis ${ }^{12}$.

Por sua vez, $Q$ e $D$ expressam conteúdos numéricos mais definidos em contraposição às variáveis $T$, l e E. Estas terão sua composição desenvolvida no decorrer da pesquisa com as subvariáveis adequadas. Por exemplo, em I (infraestrutura básica), considerar-se-á o fornecimento de energia, o tratamento de esgoto, o recolhimento período de lixo, entre outros. A variável $T$ incluirá as distâncias entre as unidades construídas (por Faixa) e os modais de transporte disponíveis.

O IFE constitui-se em um elemento de extrema importância para a avaliação adequada do programa, pois expressa aspectos técnicos que estejam explícitos ou sejam consequências de decisões tomadas pelos formuladores da política pública relevante.

Vale destacar que além dos dados obtidos empiricamente de modo autônomo, há outros obtidos do já referido Trabalho Técnico Social: os municípios, ao assinarem o Termo de Adesão com a Caixa - anexo aos contratos - passam a se responsabilizar pela execução do Trabalho Técnico Social (cláusula II) ${ }^{13}$ junto aos beneficiários dos empreendimentos implantados.

No quarto momento do estudo, o projeto utilizará a "definição quantitativa de um padrão de validação jurídica" (PVJ), referida por Castro (2018a, p.130). O Padrão de Validação Jurídica busca determinar, com referência aos elementos relacionais, as condições condizentes como a fruição, por assim dizer "ideal", ou desejável, do direito em tela. O PVJ constitui parâmetro a ser formulado com base em variadas fontes, tais como as expectativas dos titulares dos direitos, aspirações dos

\footnotetext{
${ }^{12}$ Dimensão (em $\mathrm{m}^{2}$ ) dos imóveis por quantidade de habitantes.

${ }^{13}$ Ver nota 47.
} 
movimentos sociais, diretrizes internacionais, documentos relevantes sobre a temática, etc., tudo tendo como referência geral o conjunto dos conteúdos dos pactos sociais ocorridos no processo democrático. ${ }^{14}$

Por fim, a "efetividade empírica juridicamente validada" descrita por Castro (2018, p.131) pode constituir importante meio para a satisfação de anseios de atores sociais desfavorecidos. Reformas que atendam a tais anseios poderão contribuir para evitar que a política pública focalizada acentue conflitos e se torne um foco de tensão que alimente a tendência de ingovernabilidade da democracia.

Para fins de delimitação do objeto da pesquisa, e como meio de explicitar dados mais confiáveis e contextualizados, um contorno geoespacial será utilizado. Para tanto, a capital federal foi escolhida, uma delimitação que não foi realizada arbitrariamente: há uma grande área metropolitana na qual o centro econômico da conurbação (denominado Plano Piloto) está integrado. Vale ressaltar, como afirmado anteriormente, que as regiões metropolitanas constituem um dos manifestos pontos de fragilidade para implementação dos planos diretores, por desconsiderarem as necessidades variadas do público que habita nessas áreas. Além disso, os dados utilizados nesse trabalho pertencem ao recorte temporal $2014-2017$.

Brasília foi projetada inicialmente para comportar um número de 500 mil habitantes e conta hoje com quase 3 milhões, incluindo a população das Regiões Administrativas (RAs) ${ }^{15}$, sendo atualmente a terceira maior cidade e a quinta maior concentração urbana do Brasil. As referências a Brasília, no presente trabalho, devem ser interpretadas como abrangendo a área que inclui suas 31 RAs. (GOVERNO DE BRASÍLIA, 2015)

\subsubsection{Fruição por redução do déficit habitacional: quantificação dos componentes " $Q$ " e " $D$ "}

A escolha pelo recorte geográfico que inclui as RAs mencionadas anteriormente poderá evidenciar problemas característicos do processo de urbanização brasileira. Um exemplo disso seria a relação estabelecida entre periferias destituídas de equipamentos sociais, infraestrutura básica, transporte eficiente e qualidade das unidades habitacionais. O último dado oficial sobre o déficit habitacional em Brasília é de 2014 e este número aproximava-se de 125 mil unidades habitacionais, o

\footnotetext{
${ }^{14}$ O conceito de "pacto social", adotado pela AJPE, está discutido acima, na seção 1.3.4.

${ }^{15}$ A divisão do Distrito Federal em regiões administrativas foi oficializada através da Lei no 4.545/64.
} 
que inclui habitações precárias, coabitação familiar, ônus excessivo com aluguel e adensamento excessivo. No caso brasiliense, mais da metade do déficit deve-se ao ônus excessivo com aluguel, que incide quando a locação compromete mais de $30 \%$ dos vencimentos de pessoas com renda familiar de até 3 salários mínimos. (CBI DADOS, 2014)

As faixas de renda ${ }^{16}$ constituem um dos principais atributos de composição do déficit habitacional na pesquisa abordada no presente artigo e, conforme dados obtidos, aproximadamente $83 \%$ do déficit habitacional concentram-se na classe de faixa de renda de 0 a 3 salários mínimos. As famílias que recebem de 3 a 5 salários mínimos representam 7\% do déficit; as que recebem de 5 a 10 salários mínimos, equivalem a $6 \%$ e, por fim, as que recebem mais de 10 salários mínimos correspondem a $4 \%$ do déficit. A tabela a seguir demonstra os dados: (CBI DADOS, 2014)

Tabela 2 - Déficit habitacional por faixa de renda em Brasília e Unidades contratadas no ano de 2014

\begin{tabular}{ccc}
\hline Faixa de renda & $\begin{array}{c}\text { Déficit habitacional } \\
\text { (número de } \\
\text { unidades) }\end{array}$ & $\begin{array}{c}\text { Unidades } \\
\text { contratadas via } \\
\text { MCMV }\end{array}$ \\
\hline 0 a 3 S.M & 103.750 & 6.317 \\
3 a 5 S.M. & 8.750 & 16.966 \\
5 a 10 S.M. & 7.500 & 6.728 (de 5 S.M em \\
> 10 S.M. & 5.000 & diante) \\
\hline Total & 125.000 & 30.011 \\
\hline
\end{tabular}

Fonte: (CBI DADOS, 2014)

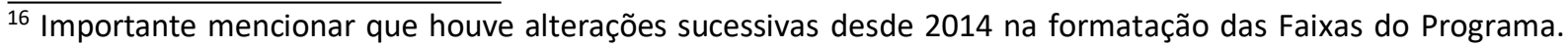
Atualmente (Abril /2019), a Faixa 1 corresponde a famílias que recebem até $\mathrm{R} \$ 1.800$; a Faixa 1,5, até $\mathrm{R} \$ 1.600$ (; a Faixa 2, até $R \$ 4.000$ e a Faixa 3, até $R \$ 9.000$.
} 
A Tabela 2 leva em consideração, como afirmado anteriormente, as Faixas de renda criadas na inauguração do programa, posto que a recente criação da "Faixa 1,5" ainda não apresenta resultados para a região. Com a exposição desses dados, torna-se nítida a desproporção entre as necessidades da maior parte da população e a realidade da produção de unidades habitacionais para esse grupo.

É claro que o resultado ideal para a diferença (quantitativa) entre a oferta e a demanda seria zero. Ou, ainda, em termos de proporção, a relação entre oferta (Q) e demanda (D) deveria ser 1 , sendo os valores menores e maiores do que 1 indicações de déficits ou superávits. Dessa forma, as unidades habitacionais seriam produzidas de modo a atender todas as necessidades existentes. As proporções referidas estão mostradas na Tabela 3 abaixo:

\section{Tabela 3: Correspondência Q e D}

$\begin{array}{ccc} & \text { Proporção } & \text { Resultado } \\ \text { Q/D } & 1 & \text { Ideal } \\ \text { Q/D } & >1 & \text { Deficitário } \\ \text { Q/D } & <1 & \text { Excedente }\end{array}$

Os dados empíricos pesquisados mostram que a oferta efetiva das unidades habitacionais está desalinhada com as proporções mencionadas, relativamente a todas as faixas de renda do Programa. Isto está evidenciado na Tabela 4, a seguir:

Tabela 4 - Razão entre Q e D e resultados obtidos 


\begin{tabular}{cccc}
\hline $\begin{array}{r}\text { Itens de } \\
\text { cálculo }\end{array}$ & Faixa 1 & Faixa 2 & Faixa 3 \\
\hline Q & 6310 & 16.966 & 6728 \\
D & 103.750 & 8.750 & 7500 \\
& & & \\
\hline $\begin{array}{c}\text { Proporção } \\
\text { Q/D }\end{array}$ & $\mathbf{0 , 0 6}$ & $\mathbf{1 , 9 3}$ & $\mathbf{0 , 8 9}$ \\
\hline
\end{tabular}

Fonte: Elaboração própria

Constata-se que, para a Faixa 1, em termos proporcionais, a quantidade de unidades habitacionais produzidas está próxima a zero (isto é, a razão de 0,06), traduzindo-se em uma fruição do direito à moradia, nesse aspecto, praticamente nula. Por outro lado, a produção de unidades para a Faixa 2 ultrapassa a necessidade do grupo-alvo, constituindo um excesso de oferta. O número de empreendimentos entregues ultrapassa em quase duas vezes a necessidade do grupo social beneficiado.

Ainda sobre os dados mostrados na Tabela 4, a Faixa 3 apresenta uma fruição próxima a 1. Entretanto, deve-se ressaltar que esse grupo possui melhores condições financeiras para aquisição de imóveis independentemente de programas habitacionais específicos. Como existem formas de financiamentos habitacionais promovidas por outras instituições bancárias (além da Caixa Econômica Federal), mesmo com taxas de juros menos atrativas, é possível que a fruição do direito à moradia pelas classes sociais representadas pela Faixa 3 seja bem maior que a indicada na Tabela 4.

Importante destacar que o evidente desalinhamento entre quantidade de imóveis construídos por Faixa do Programa a demanda é um resultado esclarecedor sobre o atual déficit habitacional no País. Em 2009, quando o Programa foi lançado, o déficit habitacional estava na casa de 5.998 milhões de domicílios e, atualmente, dez anos após a implementação do PMCMV, o número saltou para 7.770 milhões. (FGV; ABRAINC; 2018)

2.2.2 Fruição por disponibilidade de eficazes modais de mobilidade e transporte urbano: quantificação do componente relacional " $\mathrm{T}$ " 
Dando continuidade à análise, importa ressaltar que Brasília apresenta uma composição geoespacial bastante peculiar. O plano piloto centraliza as funções econômicas e de trabalho. Obviamente, o resultado é perverso: as demais Regiões Administrativas, em sua maioria, tendem a ser transformadas em verdadeiras cidades-dormitório. (SECRETARIA DE ESTADO DE GESTÃO DO TERRITÓRIO E HABITAÇÃO, 2007)

Além disso, o amparo de um planejamento urbano estratégico, no caso de Brasília, favoreceu a formação de assentamentos dispersos, separados por áreas verdes, o que afastou as demais Regiões Administrativas do Plano Piloto. O resultado traduz-se no elevado tempo de deslocamento de casa para o trabalho e vice-versa, para uma parcela majoritária da população.

A localização da moradia, juntamente com a disponibilidade de eficazes modais de mobilidade/transporte, constitui uma importante condição para o exercício pleno do direito à moradia, tal qual evidenciado pelo documento sobre a habitação ${ }^{17}$ desenvolvido previamente à Habitat III, referenciado no início deste trabalho. A integração dos moradores à malha urbana não diz respeito somente ao estabelecimento de habitações em áreas regularizadas pela administração pública. Devem ser avaliadas as opções de locomoção e, principalmente, o tempo médio gasto para o deslocamento, o que é fator relevante, tratando-se do aspecto geoespacial de Brasília.

Em relação às faixas de renda do Programa, é importante destacar que os empreendimentos desenvolvidos para a Faixa 1 são projetos viabilizados com participação mais efetiva da Administração Pública. Assim, no que se refere ao local de implementação, as Zonas Especiais de Interesse Social ${ }^{18}$ são utilizadas para essa finalidade, ou seja, a produção de moradias de baixo custo, visando atender à menor faixa de renda.

Por outro lado, as unidades para as Faixas 2 e 3 apresentam maior flexibilidade nesse sentido, pois a seleção do local depende exclusivamente do interesse econômico das incorporadoras. Desse

\footnotetext{
${ }^{17}$ Comentário Geral n. 4 ONU, tópico 8, f: “Localização. A habitação adequada deve estar em uma localização que permita acesso a opções de trabalho, serviços de saúde, escolas, creches e outras facilidades sociais. Isso é válido para grandes cidades, como também para as áreas rurais, em que os custos para chegar ao local de trabalho podem gerar gastos excessivos sobre o orçamento dos lares pobres. Similarmente, habitações não deveriam ser construídas em locais poluídos nem nas proximidades de fontes de poluição que ameacem o direito à saúde dos habitantes."

${ }^{18}$ As Zonas Especiais de Interesse Social (ZEIS) constituem em instrumento definido pelo Estatuto da Cidade, para utilização das prefeituras. Os planos diretores constituem a fonte de origem e determinação das ZEIS que objetivam reservar espaços urbanos direcionados para políticas que visem amparar parcelas da população marginalizadas e sem acesso às formas majoritárias de financiamento habitacional.
} 
modo, elas podem escolher áreas que apresentam melhores condições de atratividade para o públicoalvo, como por exemplo, o fornecimento de transporte público ágil, como o serviço de metrô.

Os moradores de Brasília utilizam como principal fonte de locomoção os veículos individuais. A distribuição modal em Brasília é dominada pelo automóvel: 39,2\% dos deslocamentos são feitos por transporte individual, contra $31,5 \%$ em coletivo, $20,7 \%$ a pé e apenas $2,3 \%$ de bicicleta. (CORREIO BRAZILIENSE, 2016)

Conforme pesquisa do IPEA, o tempo médio para deslocamento de casa para o trabalho, em pesquisa realizada em 2014, em Brasília, gira em torno de 34,9 minutos. Entretanto, não há um estudo realizado para cada Região Administrativa, considerando que algumas se situam mais próximas do Plano Piloto e outras mais distantes, esse tempo pode chegar a ser triplicado nos horários de trânsito intenso, como o período entre as $6 \mathrm{~h}$ e $9 \mathrm{~h}$ e entre $17 \mathrm{~h}$ e 20h. (MOREIRA, 2018, p. 356)

O mapa a seguir (Figura 1) visa elucidar a localização dos empreendimentos realizados do Programa Minha Casa Minha Vida em Brasília, considerando as 3 Faixas de financiamento. O mapa mostra as áreas onde se localizam os empreendimentos das Faixas 1 (assinalada com um círculo vermelho), 2 (quadriláteros amarelos) e 3 (triângulos verdes).

Figura 1 - Localização dos empreendimentos PMCMV no mapa de Regiões Administrativas

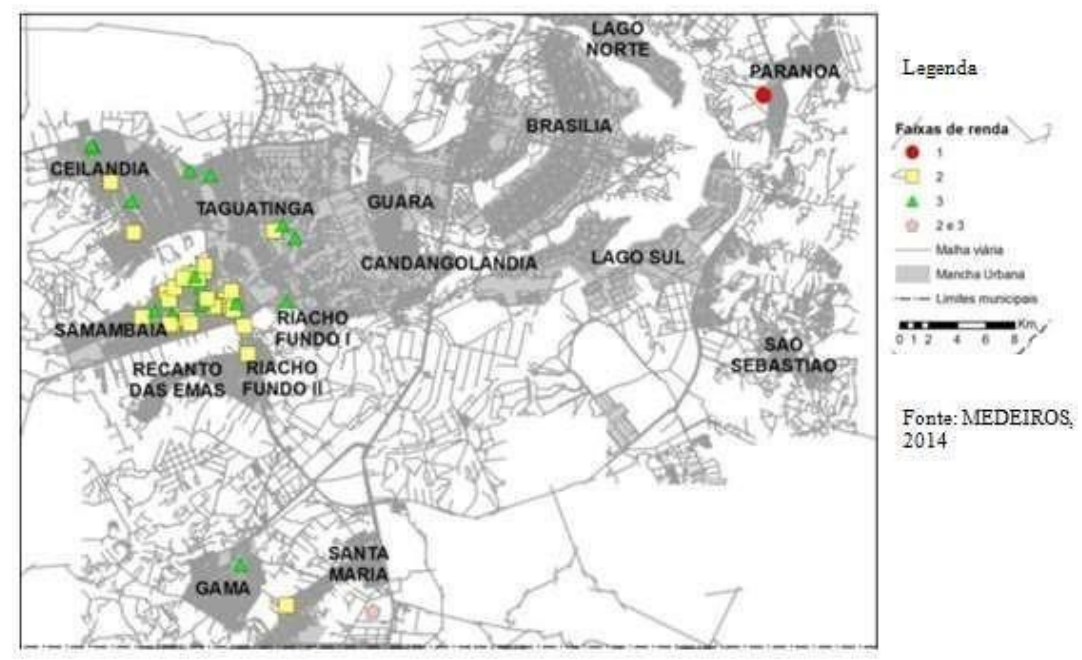


É possível perceber-se, no mapa, que há uma concentração de empreendimentos para as Faixas 2 e 3 no setor oeste (quadrantes da esquerda do mapa) e, para Faixa 1, no nordeste (quadrante direito superior do mapa), especificamente na RA Paranoá.

Em relação ao tempo de deslocamento, dois fatores negativos se acumulam: a utilização de transporte individual é predominante em todas as regiões administrativas e há uma superlotação das principais vias em horários de tráfego intenso. O resultado representa um tempo de deslocamento de uma a duas horas para um trecho de tempo médio (em condições normais e fora dos horários de pico) de 30 minutos para as cidades satélites mais populosas - Taguatinga e Águas Claras.

A situação do trânsito em Brasília é um problema generalizado. Todas as principais vias da capital são comprometidas com congestionamento intenso em horários de pico, principalmente. Portanto, as alternativas do transporte coletivo como o BRT (Bus Rapid Transit) e o Metrô contribuem para uma locomoção rápida entre os pontos de maior fluxo.

O Metrô/BRT conecta as Regiões do Gama e Santa Maria ao Plano Piloto, a previsão é de que futuramente o projeto contemple outras regiões, inclusive no setor leste. É importante ressaltar os dados mencionados de integração de transporte e cruzar as informações com a localização dos empreendimentos do Programa Minha Casa Minha Vida.

A integração de formas variadas de locomoção é apresentada como o melhor modo de se reduzir a necessidade de deslocamento pela cidade e otimizar a utilização do espaço de circulação. Portanto, para o trabalho em tela, considera-se que a conjugação de mais de um meio de transporte represente o tipo ideal de implementação em termos de política de planejamento urbano.

Para que haja satisfatória fruição do direito, considerada a varável " $\mathrm{T}$ ", é razoável entender que não basta apenas a existência das opções de locomoção, mas deve haver uma integração nítida com o objetivo de fomentar a utilização dos transportes variados. Alguns exemplos conjugariam a existência de ciclovias em bom estado e de capilarização suficiente para os interesses de locomoção dos moradores, a existência de pontos de locação e guarda de bicicletas, a possibilidade de leva-las nos vagões do metrô, entre outros. Nesse sentido, a tabela de correspondência ${ }^{19}$ obedecerá aos seguintes parâmetros:

\footnotetext{
${ }_{19}$ Designa-se aqui como "tabela de correspondência" o conjunto das convenções subjacentes à mensuração. Segundo a AJPE, que nesta matéria segue os estudos de sociologia da estatística de Alain Desrosères (ver, p. ex. Desrosières, 1998), tais convenções são subjacentes a qualquer mensuração. Na aplicação da AJPE, as convenções são estabelecidas para o fim de produzir um argumento acerca de componentes relacionais
} 


\section{Escala 1 - Escala de atribuição de valores ao componente relacional referente aos meios de transporte disponíveis}

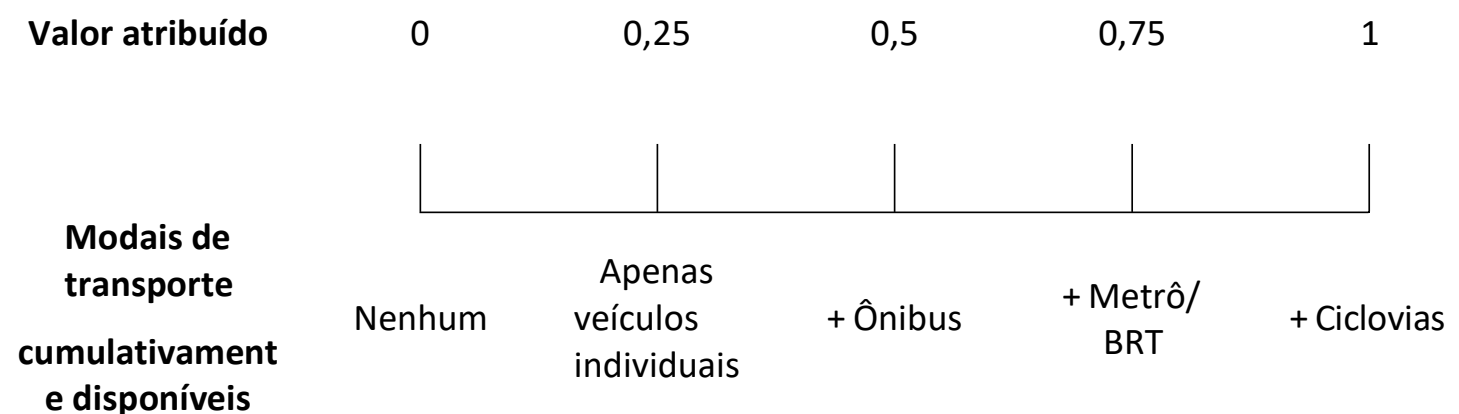

Os empreendimentos da Faixa 1, conforme indicação em mapa (Figura 1), situam-se na Região Administrativa Paranoá. Essa região não é beneficiada suficientemente por ciclovias. Ainda assim um contingente pequeno pessoas utilizam esse tipo de transporte conforme dados obtidos pela CODEPLAN DF (ver Tabela 5, abaixo):

Tabela 5 - Percentuais de utilização de modais de transporte por RA

\begin{tabular}{ccccc}
\hline \multirow{2}{*}{$\begin{array}{c}\text { Modal de } \\
\text { transporte }\end{array}$} & Paranoá & Águas Claras & Samambaia & Ceilândia \\
\cline { 2 - 5 } Ônibus & $56 \%$ & $13,2 \%$ & $47.6 \%$ & $48.9 \%$ \\
Automóvel & $23 \%$ & $63 \%$ & $24.3 \%$ & $23.9 \%$ \\
Utilitário & $0.2 \%$ & $0.1 \%$ & 0 & 0 \\
Metrô/BRT & $0 \%$ & $12.5 \%$ & $8 \%$ & $5.5 \%$ \\
Motocicleta & $2.5 \%$ & $1.3 \%$ & $2.1 \%$ & $2.1 \%$ \\
Bicicleta & $1.8 \%$ & $0.5 \%$ & $1.1 \%$ & $1.2 \%$
\end{tabular}

relevantes para a efetividade do direito subjetivo analisado (no caso presente, o direito à moradia, no contexto indicado). Ver Castro (2018b, p. 31, nota 18 ). 


\begin{tabular}{ccccc} 
A pé & $14.3 \%$ & $6.3 \%$ & $8.4 \%$ & $10.5 \%$ \\
Outros & $1.7 \%$ & $1.7 \%$ & $8.1 \%$ & $7.6 \%$ \\
\hline Total & $100 \%$ & $100 \%$ & $100 \%$ & $100 \%$ \\
\hline
\end{tabular}

Fonte: Codeplan, 2015

Sendo assim, fica evidente que a maior parte da população na RA Paranoá se locomove por meio de ônibus e automóveis, não havendo uma integração substancial de meios diversos de transporte. A ausência de linha de metrô / BRT também é um agravante para a Região, tornando o transporte deficitário do ponto de vista da fruição do direito à moradia para os beneficiados.

Estendendo a avaliação para a Faixa 2, tem-se que as Regiões mais contempladas com esses empreendimentos são Águas Claras, Samambaia e Ceilândia. Conforme dados mostrados (Tabela 5), há uma predominância da utilização de ônibus e automóveis para as 3 regiões, somando-se a isso o metrô como uma alternativa possível, mas ainda não suficiente para dar equilíbrio aos meios de transporte.

Ainda em conformidade com o mapa (Figura 1), tem-se que os empreendimentos da Faixa 3 localizam-se nas mesmas RAs que os empreendimentos para a Faixa 2. Nesse sentido, os dados se manterão para efeitos de cálculo de fruição do direito de moradia relativamente ao aspecto "disponibilidade de modais/transporte".

A partir das considerações acima, é possível conferir expressão quantitativa aos valores do componente relacional " $\mathrm{T}$ " para cada uma das faixas do PMCMV em Brasília no ano de 2014, como etapa necessária ao cálculo dos respectivos IFEs (ver Tabela 6).

Tabela 6 - Valores do componente relacional "T" segundo faixas do PMCMV em função da quantidade de modais de transporte disponíveis

\begin{tabular}{ccc}
\hline Faixas do PMCMV & $\begin{array}{c}\text { Quantidade de modais } \\
\text { de transporte }\end{array}$ & $\begin{array}{c}\text { Valor atribuído a "T", } \\
\text { segundo a Escala 1 }\end{array}$ \\
\hline $\mathrm{MF}_{1}$ & 2 & 0,5 \\
$\mathrm{MF}_{2}$ & 3 & 0,75 \\
$\mathrm{MF}_{3}$ & 3 & 0,75 \\
\hline
\end{tabular}


Fonte: elaboração da autora.

Os resultados traduzem uma informação importante: ainda que o deslocamento em Brasília represente um problema generalizado e presente em inúmeras vias de acesso às mais variadas RAs, algumas localidades contam com mais alternativas de locomoção do que outras, o que afeta a fruição do direito à moradia por diferentes indivíduos e grupos.

Diante o exposto, a população beneficiária do PMCMV Faixa 1 resta mais uma vez prejudicada, pois não tem à disposição opções diferenciadas para a locomoção urbana. São utilizados fundamentalmente veículos individuais e transporte coletivo, meios de condução considerados lentos para a atual conjuntura do trânsito na capital. Por outro lado, as Faixas 2 e 3 contam com um importante meio de transporte: o metrô. O que permite um deslocamento mais ágil até o centro econômico e comercial da região, o Plano Piloto.

2.2.3 Fruição relativa a Serviços de Infraestrutura Básica: quantificação do componente "I"

Retomando a discussão promovida no início do presente artigo, a fruição do direito à moradia não pode ser avaliada exclusivamente pelo critério de existência de "4 paredes e um teto". Vários fatores devem estar presentes para se considerar adequada a fruição do direito. A mera construção de unidades habitacionais não representa resolução do problema, se essas forem executadas sem garantir a utilização do espaço de forma ampla, bem como se equipamentos de infraestrutura básica estiverem ausentes.

Nesse sentido, a Infraestrutura Básica constitui é um importante componente relacional para a avaliação da fruição do direito à moradia. Nesta subseção, considera-se que o componente I seja o agregado da disponibilidade empírica dos seguintes serviços urbanos: abastecimento de água, esgotamento sanitário, acesso à energia elétrica e coleta de lixo. Para fins de quantificação de I, a seguinte escala é proposta: 
Escala 2 - Escala de atribuição de valores ao componente relacional I, considerando o acesso aos serviços urbanos: abastecimento de água, esgotamento sanitário, energia elétrica e coleta de lixo.
Valor de I
0
0,25
0,5
0,75
1

\section{Quantidade de serviços urbanos disponíveis}

0

1

2

3

4

O cruzamento (i) dos dados empíricos relativos ao acesso a serviços urbanos em diferentes regiões administrativas com (ii) sua expressão em termos de valores de I, calculados segundo a escala da Figura 3, proposta acima, permitirá quantificar a fruição do componente relacional "infraestrutura básica" relacionada aos empreendimentos de cada uma das faixas do PMCMV em Brasília, no ano de 2015. Para tanto, são primeiramente apresentados os dados relativos ao acesso empírico a serviços urbanos, por região:

Tabela 7 - Acesso a serviços urbanos, por RA de Brasília, no ano de 2015, e respectivos valores de I

\begin{tabular}{ccccc}
\hline \multirow{2}{*}{ Serviço urbano } & \multicolumn{4}{c}{ Regiōes Administrativas } \\
\cline { 2 - 5 } & Paranoá & Águas Claras & Samambaia & Ceilândia \\
\hline Abastecimento de água & $98,5 \%$ & $99.4 \%$ & $99.5 \%$ & $98.3 \%$ \\
Esgotamento sanitário & $95.2 \%$ & $84.4 \%$ & $97.1 \%$ & $80.7 \%$ \\
Energia elétrica & $98.7 \%$ & $98.1 \%$ & $100 \%$ & $98.2 \%$ \\
Coleta de lixo & $99.3 \%$ & $90.9 \%$ & $99.3 \%$ & $85.4 \%$ \\
\hline Média & $97,9 \%$ & $98,2 \%$ & $98,9 \%$ & $90,65 \%$ \\
\hline Valor de S & 0,979 & 0,982 & 0,989 & 0,9065 \\
\hline
\end{tabular}

Fonte: Codeplan, 2015 e elaboração da autora 
Importante destacar que os valores obtidos refletem uma circunstância peculiar da região eleita. Os serviços de infraestrutura básica são oferecidos de forma quase padronizada por toda a capital, indicando que, independentemente da distância do centro econômico, os variados setores elencados no trabalho contam com os serviços de abastecimento de água, esgotamento sanitário, energia elétrica e coleta de lixo periódica.

Mesmo assim, a RA Ceilândia apresenta dados destoantes das demais regiões. Para evitar possíveis distorções na obtenção do IFE de infraestrutura básica pra Faixas 2 e 3, essa RA apresentará um IFE separadamente, visando tornar os resultados mais fidedignos à realidade.

Portanto, para esta variável, os dados obtidos mantêm-se muito próximos uns dos outros e bastante próximos do padrão em todas as Faixas analisadas. Comparando com os outros valores apurados no trabalho, deve-se admitir que a infraestrutura básica em Brasília representa uma característica singular em comparação com o resto do País. Importante notar que, no caso de Brasília, o abrangente planejamento prévio - um aspecto incomum das cidades brasileiras - pode ter contribuído para este resultado.

2.2.4 Fruição relativa ao aspecto da estrutura/dimensão: quantificação do componente "E"

Para a construção do argumento que dê relevância ao tópico de fruição quanto à estrutura/dimensão do imóvel construído, vale destacar que, nos projetos do PMCMV especificamente direcionados para a Faixa 1, há uma planta básica, a qual, em virtude de determinação legal, não pode sofrer alterações. Para as casas, a "tipologia 1" apresenta a dimensão máxima de $35 \mathrm{~m}^{2}$ (com área interna de $32 \mathrm{~m}^{2}$ ). No caso dos apartamentos ("tipologia 2 "), o tamanho amplia-se para $42 \mathrm{~m}^{220}$. Em relação aos compartimentos, estes são os mesmos independentemente da tipologia (1 ou 2): sala, cozinha, banheiro e dois dormitórios. (MINISTÉRIO DAS CIDADES, 2017)

Deve-se ter em mente que a dimensão do imóvel que servirá como habitação para as famílias beneficiadas é um importante componente para a análise de fruição do direito à moradia. $O$ espaço

\footnotetext{
20 MINISTÉRIO DAS CIDADES (2017). Portaria 269, de 22 de março de 2017: Dispõe sobre as diretrizes para a elaboração de projetos e aprova as especificações mínimas da unidade habitacional e as especificações urbanísticas dos empreendimentos destinados à aquisição e alienação com recursos advindos da integralização de cotas no Fundo de Arrendamento Residencial - FAR, e contratação de operações com recursos transferidos ao Fundo de Desenvolvimento Social - FDS, no âmbito do Programa Minha Casa, Minha Vida - PMCMV.
} 
físico disponível em cada cômodo, a planta inicial, a estrutura da casa ou apartamento, refletem diretamente condições relativas ao bem-estar dos beneficiários do Programa. A moradia deve ter tamanho adequado para o desempenho das atividades domésticas, iluminação e temperatura confortáveis, bem como espaço para lazer e descanso dos moradores.

O Comentário Geral n. 4 da ONU enfatiza o espaço como importante atributo de sustentação do direito à moradia digna:

d. Habitabilidade. A habitação adequada deve ser habitável, em termos de prover os habitantes com espaço adequado e protegê-los do frio, umidade, calor, chuva, vento ou outras ameaças à saúde, riscos estruturais e riscos de doença. A segurança física dos ocupantes deve ser garantida. O Comitê estimula os Estados-partes a, de modo abrangente, aplicar os Princípios de Saúde na Habitação, preparados pela OMS, que veem a habitação como o fator ambiental mais frequentemente associado a condições para doenças em análises epidemiológicas, isto é, condições de habitação e de vida inadequadas e deficientes são invariavelmente associadas com as mais altas taxas de mortalidade e morbidade. (UNITED NATIONS, 1991)

A dimensão física dos imóveis construídos é, portanto, um elemento de imprescindível análise, posto que se relaciona diretamente com a qualidade de vida que os beneficiários obterão. 0 "morar" com dignidade só é possível se a estrutura das unidades construídas permite a acomodação, em padrões de espaço minimamente confortáveis e salubres, das famílias às quais o Programa se destina. Levando em consideração a Faixa 1 do Programa, é possível a construção de um diagnóstico desenhado através do cruzamento de dados da taxa de fecundidade por R.A. Ressalta-se que a taxa de fecundidade representa um indicador demográfico bastante útil para o planejamento de políticas públicas, pois trata-se de uma estimativa da quantidade de filhos que uma mulher teria ao logo da sua vida reprodutiva. Em geral, os governos utilizam esse dado para perspectivas sobre crescimento ou decréscimo populacional e para estabelecer a média do tamanho das famílias.

O último dado divulgado que realiza a conjugação das duas informações afirmou que a taxa de fecundidade das famílias de baixa renda no Brasil aproxima-se de 2,9 filhos por mulher, já nas classes média e alta, o número cai para 1,73. (UNFPA, 2018)

Nesse sentido, considerando um arranjo familiar composto cinco pessoas (considerando ambos: baixa renda e Faixa 1 do PMCMV), $32 \mathrm{~m}^{2}$ parece bastante inadequado para que essa família 
exerça o seu direito à moradia com dignidade. Vale destacar que há determinação mínima dimensional para os imóveis construídos no Brasil, a NBR 15575 / ABNT.

A NBR 15575 afirma que "Para os projetos de arquitetura de unidades habitacionais, sugerese prever no mínimo a disponibilidade de espaço nos cômodos da edificação habitacional para colocação e utilização dos móveis e equipamentos-padrão listados no Anexo G [da norma] ${ }^{21 "}$. (BRASIL, 2013, p. 36)

Leite e Oliveira (2007, p. 2) demonstraram preocupação sobre a redução paulatina na dimensão dos imóveis produzidos no mercado brasileiro em geral:

Um dos principais "reflexos na qualidade de vida das pessoas" pode ser observado nos espaços internos das habitações. Invariavelmente o tamanho das habitações tem diminuído drasticamente tornando-os diminutos, claustrofóbicos e com capacidade de mobiliamento desprezível. A falta de qualidade destes espaços não se restringe às habitações populares como se imagina. Em recente pesquisa em feira de imóveis considerados como de Alto Padrão e preços variando entre meio e um milhão de reais, notou-se, ao contrário do que se espera, por exemplo, que na maioria dos dormitórios do casal torna-se impossível instalar uma cama "king size", os banheiros da suíte não são muito maiores do que os das habitações populares. As áreas de serviço têm tamanho ínfimo e tão demasiadamente vinculadas com a cozinha que se pode confundir uma com a outra.

Simone Villa e Rotelli $(2012$, p.8) importantes pesquisadores da área afirma que a falta de qualidade e eficiência nos produtos escolhidos para a construção da obra é um outro grave problema das construções destinadas à Faixa 1 do PMCMV. Parte das unidades habitacionais erguidas no conjunto habitacional apreciado pela autora apresentaram rachaduras e infiltrações antes mesmo da entrega das casas. Simone afirma que, além disso, não houve atendimento aos critérios mínimos de conforto, como iluminação, ventilação e espacialidade dos cômodos, incluindo uma orientação inadequada dos cômodos em relação ao sol e vento, ou ainda a escolha errônea das esquadrias e aberturas e demais decisões projetuais. A autora afirma, além disso, que em geral as habitações do PMCMV, na Faixa 1, possuem dois quartos, sendo um destinado ao casal e outro aos filhos. Entretanto,

\footnotetext{
${ }^{21}$ ANEXO G (NBR 15575) “Dimensões mínimas e organização funcional dos espaços Este anexo informativo visa apresentar como sugestão algumas das possíveis formas de organização dos cômodos e dimensões compatíveis com as necessidades humanas" - O Anexo G traz a recomendação de que os projetos de arquitetura de edifícios habitacionais prevejam no mínimo a disponibilidade de espaço nos cômodos do edifício habitacional para colocação e utilização dos móveis e equipamentos-padrão listados.
} 
em diversos quartos são inseridos beliches, colchões e sofás para comportar os moradores. As más condições de habitabilidade tornam também comum o fato de as crianças dormirem com os pais por falta de espaço na moradia. Os quartos acabam tornando-se áreas de depósito, uma vez que a unidade não comporta áreas e mobílias específicas para estocagem. Deve-se destacar que há uma tendência na variação da composição familiar. A composição familiar tradicional tem cedido espaço para novos rearranjos familiares não atendidos pela perspectiva das unidades. Para fins de análise posicional, esse trabalho considerará a composição familiar mais frequente que, na relação de espaço por habitante, é a que exige maiores dimensões em termos de espaço físico. A título de ilustração, duas tabelas serão apresentadas a seguir. Uma demonstra o histórico evolutivo das regras pertinentes à dimensão dos imóveis no Brasil. A outra permite demonstrar as alterações das dimensões que os imóveis têm sofrido, considerada a metragem quadrada por pessoa:

Tabela 8 - Histórico de área mínima para habitação $\left(\mathrm{m}^{2}\right)^{22}$

\begin{tabular}{|c|c|c|c|c|c|c|c|}
\hline Estudo & Quarto & Quarto & Sala & Cozinha & Banho & serviço & $\begin{array}{l}\text { Área } \\
\text { total }\end{array}$ \\
\hline $\begin{array}{l}\text { Código Sanitário } \\
\text { (1978) }\end{array}$ & 8,00 & 6,00 & 8,00 & 4,00 & 2,00 & - & 28,00 \\
\hline Silva (1982) & 7,75 & 7,80 & 10,50 & 3,57 & 2,40 & 2,10 & 34,12 \\
\hline IPT (1987) & 9,00 & 8,00 & 12,00 & 10,00 & 2,50 & 1,50 & 43,00 \\
\hline Boueri (1989) & 14,00 & 12,00 & 15,00 & 7,20 & 4,20 & 5,40 & 57,80 \\
\hline Voordt (1990) & 13,34 & 10,56 & 25,52 & 6,84 & 5,71 & - & 61,97 \\
\hline $\mathrm{CDHU}-$ & 8,12 & 6,94 & 16,73 & 9,05 & 2,88 & 1,96 & 45,68 \\
\hline $\begin{array}{l}\text { Piratininga } \\
\text { (1996) }\end{array}$ & & & & & & & \\
\hline CDHU - & 13,18 & 13,18 & 13,18 & 8,44 & 2,81 & 1,63 & 52,42 \\
\hline $\begin{array}{l}\text { Brasilândia } \\
\text { (1996) }\end{array}$ & & & & & & & \\
\hline
\end{tabular}

\footnotetext{
22 Histórico do conjunto de legislações e trabalhos técnicos desenvolvidos por arquitetos sobre a temática de dimensão de imóveis no Brasil.
} 


\begin{tabular}{llllllll} 
CDHU - Básico & 8,18 & 8,18 & 11,78 & 4,87 & 3,04 & 1,82 & 37,87 \\
$\begin{array}{l}\text { (1998) } \\
\text { CDHU (2008) }\end{array}$ & 9,00 & 8,00 & 12,50 & 5,00 & 2,80 & 2,80 & 40,10 \\
\hline
\end{tabular}

Fonte: (BARCELOS, 2011, p. 66)

Diante essa exposição de documentos acerca das dimensões mínimas para cada cômodo específico e as dimensões totais, é fácil observar que a última regra que permitiu a construção de um imóvel tão pequeno foi o Código Sanitário de 1978.

\section{Gráfico 1 - Histórico de $\mathrm{m}^{2}$ por morador ${ }^{23}$}

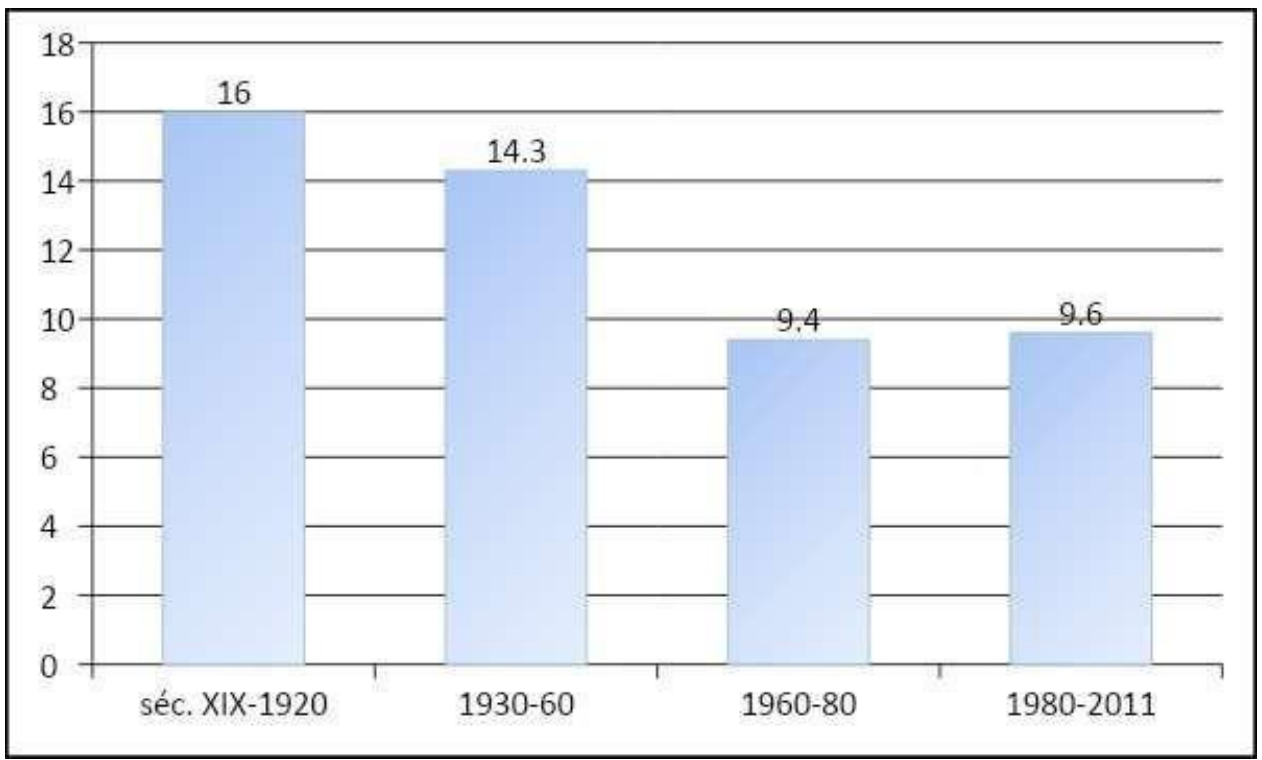

Fonte: (BARCELOS, 2011, p. 69)

O gráfico supra reproduzido traz uma noção histórica da alteração das dimensões em relação ao número de moradores dos imóveis. Kátia Barcelos também cita outros autores que realizaram estudos sobre o tamanho adequado da habitação por número de pessoas. Um exemplo é Gerard Blachère, estudioso segundo o qual, para uma qualidade de vida regular, a área útil de uma habitação

\footnotetext{
${ }^{23}$ Média histórica do tamanho dos imóveis em relação à quantidade de moradores.
} 
por pessoa deveria ser de $14 \mathrm{~m}^{2}$, e para uma qualidade de vida média, $18 \mathrm{~m}^{2}$. Além disso, outro autor citado por Barcelos, Chombart de Lauwe, famoso sociólogo urbano, assegura que a dimensão de $8 \mathrm{~m}^{2}$ de área útil por pessoa pode causar graves consequências negativas à saúde. (BARCELOS, 2011, p. 69)

Para calcular a média do tamanho das famílias por Região Administrativa, foram utilizados dados referentes à taxa de fecundidade nesses locais:

Tabela 9: Taxa de Fecundidade por Região Administrativa

\begin{tabular}{cc}
\hline $\begin{array}{c}\text { Região } \\
\text { Administrativa }\end{array}$ & $\begin{array}{c}\text { Taxa de } \\
\text { Fecundidad } \\
\mathbf{e}\end{array}$ \\
\hline Paranoá (Faixa 1) & 2,02 \\
Águas Claras (Faixa 2 e & 1,92 \\
3) & 1,81 \\
Samambaia (Faixas 2 e \\
3) \\
Ceilândia (Faixas 2 e 3) & 1,56 \\
\hline Fonte: Governo do Distrito Federal (2015)
\end{tabular}

Conforme indicação da Tabela 9, a taxa de fecundidade média para as Faixas 2 e 3, considerando as Regiões Administrativas indicadas, corresponde ao valor de 1,76. Já, para a Faixa 124, cuja taxa de fecundidade das famílias é de 2,02, e a dimensão dos imóveis varia entre $32 \mathrm{~m}^{2}$ e $42 \mathrm{~m}^{2}$, a razão existente entre espaço $\left(\mathrm{m}^{2}\right)$ por residente varia entre $7,96 \mathrm{~m}^{2}\left(32 \mathrm{~m}^{2} /\right.$ família composta por 4 integrantes ${ }^{25}$ ), e $10,44 \mathrm{~m}^{2}$ (no caso do apartamento).

Importante destacar que não há limite de tamanho máximo para os imóveis destinados às Faixas 2 e 3. De acordo com pesquisas realizadas nos sites das incorporadoras (MRV, por exemplo) ${ }^{26} \mathrm{e}$ corretores de imóveis, as dimensões para a Faixa 2 iniciam-se nos $44 \mathrm{~m}^{2}$ e encerram-se nos $65 \mathrm{~m}^{2}$ e para

\footnotetext{
${ }^{24}$ Ministério das Cidades, 2017.

${ }^{25}$ Ressalta-se mais uma vez que, embora seja nítida a tendência na variação da composição familiar tradicional, para fins de análise posicional esse trabalho considerará a composição familiar mais frequente que, na relação de espaço por habitante, é a que exige maiores dimensões em termos de espaço físico.

${ }^{26}$ MRV: https://www.mrv.com.br/minhacasaminhavida; Rossi: http://www.rossiresidencial.com.br/minha-casaminha-vida; Tenda: https://www.tenda.com/programa-minha-casa-minha-vida/
} 
a Faixa 3, entre $70 \mathrm{~m}^{2}$ e $80 \mathrm{~m}^{2}$. Para fins de utilização da Análise Posicional, a tabela abaixo servirá como parâmetro de avaliação:

Tabela 10 - Avaliação de funcionalidade de imóvel: espaciosidade por quantidade de moradores e Faixa do PMCMV27

\begin{tabular}{ccccc}
\hline Faixa & $\begin{array}{c}\text { Tamanho } \\
\text { unidade em } \\
\left(\mathbf{m}^{\mathbf{2}}\right)\end{array}$ & $\begin{array}{c}\text { Quantidade } \\
\text { média de } \\
\text { moradores } \\
\text { aproximada }\end{array}$ & $\begin{array}{c}\text { Resultado por } \\
\text { morador }\end{array}$ & Avaliação \\
\hline Faixa 1 & $\begin{array}{c}37 \mathrm{~m}^{2} \text { (média) } \\
\text { Faixa 2 }\end{array}$ & 4,02 & $9,20 \mathrm{~m}^{2}$ & Inadequado: 0 \\
Faixa 3 & $54,5 \mathrm{~m}^{2}$ & 3,76 & $14,49 \mathrm{~m}^{2}$ & Regular: 0,5 \\
(média) & $75 \mathrm{~m}^{2}$ (média) & 3,76 & $19,94 \mathrm{~m}^{2}$ & Ótimo: 1
\end{tabular}

Fonte: Elaboração da autora com base nos estudos de Gerard Blachère e Chombart de Lauwe associados ao tamanho

\subsection{5 Índice de Fruição Empírica por Faixa do PMCMV}

Ao agregar os resultados da quantificação de cada um dos componentes relacionais, inicialmente feita em separado, obtêm-se os IFEs do direito à moradia no contexto do PMCMV em Brasília, para cada faixa do programa. Para facilidade de visualização, os valores correspondentes a cada componente foram dispostos na Tabela 8, seguida das equações respectivas a cada faixa:

\footnotetext{
${ }^{27}$ Tabela construída a partir dos seguintes dados: tamanho médio dos imóveis por Faixa do PMCMV; tamanho médio das famílias por faixa de renda (considerando a taxa de fecundidade) e; Resultado, levando em consideração as metragens indicadas pelos autores abordados.
} 
Tabela 11 - Componentes relacionais do IFE relativo às faixas de renda do PMCMV em Brasília, 2015

\begin{tabular}{cccc}
\hline $\begin{array}{c}\text { Componente } \\
\text { relacional }\end{array}$ & Faixa 1 $\left(\mathrm{M}_{1}\right)$ & Faixa 2 $\left(\mathrm{M}_{2}\right)$ & Faixa 3 $\left(\mathrm{M}_{3)}\right.$ \\
\hline Proporção Q/D & 0,06 & 1,93 & 0,89 \\
$\mathrm{~T}$ & 0,5 & 0,75 & 0,75 \\
I & 0,979 & 0,98 & 0,98 \\
E & 0 & 0,5 & 1 \\
\hline
\end{tabular}

Fonte: elaboração da autora

Expressão Padrão:

$$
M F=\underline{(Q / D)+(T+I+E) 4}
$$

Então,

$$
M F_{1}=\frac{(0,06)+(0,5+0,979+0)}{4}
$$

$$
M F_{2}=\frac{(1,93)+(0,75+0,98+0,5)}{4}
$$

$$
M F_{3}=\frac{(0,89)+(0,75+0,98+1)}{4}
$$


Portanto,

$\begin{array}{ll}\mathrm{MF}_{1} & 0,38 \\ \mathrm{MF}_{2} & 1,04 \\ \mathrm{MF}_{3} & 0,9\end{array}$

Após a inclusão dos dados obtidos pelas variáveis eleitas, observa-se que o direito à moradia, proporcionado pelo PMCMV, em Brasília, entre 2014 e 2017, apresenta graus de fruição diferenciada, conforme as diferentes faixas de renda. Especificamente, a Faixa 1 apresentou o menor IFE. A fruição do direito à moradia por esse grupo mostra-se excessivamente precária, alcançando menos da metade do nível máximo de fruição no que concerne as variáveis escolhidas, que, de acordo com as convenções estabelecidas acima, deveria ser 1.

Por outro lado, as Faixas 2 e 3 exibem um IFE comparativamente melhor, e os principais motivos residem na razão $Q-D$ e na variável " $E$ ", ou seja, a quantidade de imóveis que atendem as Faixas 2 e 3 é mais que suficiente em relação à demanda existente, além de possuírem uma dimensão relativamente ampla para o tamanho das famílias que se beneficiam das unidades destinadas a elas.

Ressalte-se que a variável I não apresenta oscilações significativas em relação as Faixas de renda do Programa. Isto se explica, conforme sugerido, em decorrência de uma particularidade do Distrito Federal que possui alta infraestrutura independentemente da região administrativa analisada. Obviamente, essa análise não pode se estender para outros estados.

Outro ponto importante refere-se ao IFE alcançado pela Faixa 3: 0,9. A variável responsável pelo valor menor que o designado para a Faixa 2 é a correspondente ao Q - D. Nesse sentido, os dados podem passar uma impressão equivocada, distorcida da realidade, uma vez que embora a quantidade de imóveis produzidos em sede do PMCMV para a Faixa 3 seja menor que os direcionados para a Faixa 2, a Faixa 3 é composta por uma classe social com maior poder aquisitivo, o que permite o acesso desse grupo a outras fontes de financiamento, fora do âmbito do Programa. Uma análise que incorporasse todas as formas de financiamento utilizadas pela classe social correspondente à do público alvo da Faixa 3 solucionaria essa distorção rapidamente. Entretanto, tal investigação não foi realizada nesse trabalho, mas certamente poderá integrar pesquisa a ser desenvolvida posteriormente. 


\subsubsection{Padrão de Validação Jurídica}

Conforme descrito anteriormente, o PVJ na AJPE tenciona indicar certas condições que necessitariam estar presentes para que ocorresse a fruição, por assim dizer, ideal do direito analisado. Nesse sentido, o PVJ constitui um parâmetro a ser alcançado. A elaboração do PVJ, que é uma projeção do IFE, pode levar em consideração diversos referenciais, inclusive aspirações de movimentos sociais, diretrizes internacionais, outros documentos relevantes sobre a temática, etc. De acordo com Castro (2018, p. 33), os IFEs construídos a partir de pesquisas empíricas comparativas que indiquem desigualdades existentes entre objetos de estudos, no caso a fruição de um mesmo direito, em localidades distintas de uma cidade, podem subsidiar a constituição de um PVJ elaborado com o escopo de diminuir ou eliminar essa desigualdade.

Nesse sentido, a constituição do PVJ no presente trabalho utiliza como base a fundamentação e os resultados obtidos pelos IFEs em cada Faixa do Programa. Sendo assim, o PVJ para o PMCMV, por faixa de renda, estrutura-se a partir dos valores "adequados" de fruição empírica para cada variável utilizada na composição das condições de fruição do direto à moradia previstas na política pública examinada. Portanto, a quantidade de imóveis destinados a cada Faixa do Programa (considerando a demanda por unidades); a disponibilidade de modais de mobilidade / transporte nas localidades em que as unidades são construídas (considerando os modais de transporte disponíveis e distância para acesso ao trabalho); a infraestrutura básica (considerando água, esgoto, recolhimento de lixo, etc); a estrutura dos imóveis (considerando o tipo médio de estrutura familiar e as metragens da área dos imóveis dos beneficiários em cada Faixa), todos esses elementos considerados em sua capacidade adequada de oferta, correspondem conjuntamente, ao Padrão de Validação Jurídica para o PMCMV.

Isso significa dizer que, para a Faixa 1, por exemplo, o PVJ deve considerar valores quantitativos de produção de unidades bastante superiores aos existentes. Além disso, a localização deve ser pensada a partir dos modais de transporte disponíveis ou de uma menor distância entre as áreas destinadas para a construção dos imóveis e o núcleo econômico da região. Por fim, o PVJ da Faixa 1, deve conter um padrão específico de planta de imóvel que seja apto a acomodar com qualidade as famílias beneficiárias do Programa.

Essas observações representam, para além da constituição do PVJ, algumas linhas gerais que possam indicar a "elaboração de propostas de reformas de políticas públicas mutuamente 
complementares", que seria a última etapa da Análise Posicional na AJPE. Considerando 1 como valor ideal de fruição do direito à moradia no âmbito do PMCMV, e considerando a análise de cada variável individualmente, é possível fundamentar a formulação de novas diretrizes técnicas para os documentos que norteiam a execução da política pública em tese.

Dessa forma, as reformas sugeridas, fundamentadas amplamente nas pesquisas realizadas, podem se tornar um meio adequado e mesmo crucial para assegurar a eficácia do direito no sentido específico da fruição empírica.

\section{Considerações finais}

A última etapa da Análise Posicional consiste na "elaboração de propostas de reformas de políticas públicas mutuamente complementares" e representa, em termos gerais a possibilidade de que, diante de uma disparidade entre os valores obtidos pelo IFE e os indicados no PVJ, o jurista "proponha reformas ao quadro normativo que dá base às políticas públicas relevantes, visando assegurar a eficácia do direito legal objeto da análise". (CASTRO, 2018, p. 33)

Seria desejável a elaboração de propostas de reformas do PMCMV que tivessem por objetivo suprir as deficiências apontadas a respeito da efetividade do direito à moradia dos membros do Programa pertencentes à Faixa 1. Algumas indicações genéricas de tais possíveis reformas podem ser dadas aqui.

Quanto ao componente relacional " $Q-D$ ”, providências necessitam ser tomadas a fim de que a oferta de imóveis aumente para Faixa de Renda 1. O aporte de mais investimentos ou critérios de financiamento mais benéficos (visando igualmente a ampliação da oferta de imóveis) seriam importantes.

No que se refere ao componente relacional T, parece claro que, para assegurar a fruição do direito à moradia dos beneficiários do Programa, seria necessário ou estabelecer critérios de escolha de localizações dos projetos beneficiados por modais e serviços de transporte satisfatórios, ou investir na oferta de tais condições nas localidades em que forem construídas novas unidades.

Sobre o componente relacional I, ressalta-se, mais uma vez, que os valores apresentados da pesquisa realizada em Brasília podem não ter correspondência em outras regiões do País, tendo em 
vista que houve um planejamento prévio do processo urbanizatório na capital. Tendo em vista essa consideração, deve-se analisar esse componente em outras cidades brasileiras a fim de verificar o possível comprometimento da fruição do direito à moradia, no contexto do PMCMV, caso as disparidades sejam influentes.

Por fim, as unidades construídas devem, no mínimo, atender aos padrões de composição familiar das famílias beneficiadas pelo Programa, posto que essa relação (espaço / morador) interfere nitidamente na fruição do direito em tela. Essa ressalva é feita, obviamente, para a Faixa 1 do PMCMV, tendo em vista que as Faixas 2 e 3 tem suas dimensões livres de regulamentação, como descrito anteriormente.

REFERÊNCIAS

BARCELOS, Kátia Alves (2011). Método para avaliação de projetos de habitação social: mobiliamento, espaciosidade e funcionalidade. 2011. Dissertação de Mestrado. Universidade Federal do Mato Grosso, Faculdade de Arquitetura, Engenharia e Tecnologia, Programa de Pós-graduação em Engenharia e Edificações Ambiental. 263 fl. Disponível em < http://200.129.241.80/ppgeea/sistema/dissertacoes/4.pdf> Acesso em 25 março 2019.

BRASIL (2013). ASSOCIAÇÃO BRASILEIRA DE NORMAS TÉCNICAS (ABNT). NBR 15.575-1: Edifícios habitacionais - Desempenho. Parte 1: Requisitos Gerais. Rio de Janeiro: ABNT, 2013. Disponível em $<$ https://360arquitetura.arq.br/wp-content/uploads/2016/01/NBR_15575-1_2013_Final-RequisitosGerais.pdf> Acesso em 20 março 2019.

CAIXA ECONÔMICA FEDERAL (2017). Minha Casa, Minha Vida. Disponível em < http://www.caixa.gov.br/voce/habitacao/minha-casa-minha-vida/Paginas/default.aspx $>$ Acesso em 22 março 2019.

CASTRO, Marcus Faro de (2014). Novas perspectivas jurídicas sobre a reforma de políticas públicas no Brasil. Revista de Direito da Universidade de Brasília. Revista vinculada ao programa de pósgraduação em Direito da Universidade de Brasília. janeiro - junho de 2014, volume 1, número 1.

CASTRO, Marcus Faro de (2018). Análise Jurídica da Política Econômica. In in M. F. de Castro e H. L. P. Ferreira, orgs., Análise Jurídica Da Política Econômica: A Efetividade dos Direitos Na Economia Global. Curitiba: Editora CRV, 2018

CASTRO, Marcus Faro de (2018a). A concepção jurídica da propriedade na sociedade de mercado: aspectos de sua evolução e desafios recentes. in M. F. de Castro e H. L. P. Ferreira, orgs., Análise Jurídica Da Política Econômica: A Efetividade dos Direitos Na Economia Global. Curitiba: Editora CRV, 2018.

CASTRO, Marcus Faro de (2018b). Introdução - Perspectivas Sobre as Relações Entre o Direito e Processos Econômicos in M. F. de Castro e H. L. P. Ferreira, orgs., Análise Jurídica Da Política Econômica: A Efetividade dos Direitos Na Economia Global. Curitiba: Editora CRV, 2018 
CBI DADOS (2014). Câmara brasileira da Indústria da Construção. Déficit habitacional no Brasil. Disponível em <http://www.cbicdados.com.br/menu/deficit-habitacional/deficit-habitacional-nobrasil> Acesso em 02 abril 2017.

CODEPLAN (2015). Pesquisa Distrital por Amostra de Domicílios. Disponível em <http://www.codeplan.df.gov.br/images/CODEPLAN/PDF/pesquisa_socioeconomica/pdad/2016/PD AD_Distrito_Federal_2015.pdf > Acesso em 14 abril 2017.

CONSELHO DE ARQUITETURA E URBANISMO (2016). CAU.BR. Conheça os 30 pontos fundamentais da Nova Agenda Urbana. Disponível em <http://www.caubr.gov.br/conheca-os-30-pontos-de-acaofundamentais-para-a-implementacao-da-nova-agenda-urbana/> Acesso em 12 abril 2017.

CORREIO BRAZILIENSE (2016). Distrito federal tem 55 carros para cada 100 habitantes. Disponível em <http://www.correiobraziliense.com.br/app/noticia/cidades/2016/05/25/interna_cidadesdf,533399/ distrito-federal-tem-55-carros-para-cada-100-habitantes.shtml> Acesso em 1 maio 2017.

FGV; ABRAINC (2018). Análise das Necessidades Habitacionais e suas Tendências para os Próximos Dez Anos. Disponível em <https://www.abrainc.org.br/wp-content/uploads/2018/10/ANEHABEstudo-completo.pdf> Acesso em 20 março 2019.

GOVERNO DE BRASÍLIA (2015). Geografia. Disponível em <http://www.brasilia.df.gov.br/index.php/2015/10/21/333/>. Acesso em 02 maio 2017.

GOVERNO DO DISTRITO FEDERAL (2015). Saúde DF: Relatório epidemiológico sobre natalidade, Região de Saúde Leste, Sul, Norte, Sudoeste e Oeste. Disponível em $<$ http://www.saude.df.gov.br/wpconteudo/uploads/2018/03/Relatorio_natalidade_Regiao_Leste_2015_LA.pdf> Acesso em 20 abril 2019.

HABITAT III (2015). Documentos temáticos da habitat III: 20 - habitação. Disponível em <https://www2.habitat3.org/bitcache/ff6a0f2efbe2e7d0422d96854fceb829dc1f7f17?vid=580474\&di sposition=inline\&op=view> Acesso em 12 abril 2017.

HABITAT INTERNATIONAL COALITION (2016). Statement at Habitat III: Toward a Human Rights Habitat. Disponível em < http://www.hlrn.org/img/documents/Habitat_Ill_Statement.pdf > Acesso em 2 maio 2017.

IPEA (2016). A trajetória brasileira em busca do direito à cidade: os quinze anos de Estatuto da Cidade e as novas perspectivas à luz da Nova Agenda Urbana In Estatuto da Cidade e a Habitat III. Disponível em <http://www.ipea.gov.br/portal/images/stories/PDFs/livros/livros/160920_estatuto_cidade_cap00.p df $>$. Acesso em 10 abril 2017.

IPEA (2016a). Habitação e assentamentos precários no Brasil: Trajetória e desafios para o alcance da justiça espacial in Estatuto da Cidade e a Habitat III. Disponível em <http://www.ipea.gov.br/portal/images/stories/PDFs/livros/livros/160920_estatuto_cidade_cap13.p df> Acesso em 10 abril 2017.

MINISTÉRIO DAS CIDADES (2017). Portaria 269, de 22 de março de 2017. DIÁRIO OFICIAL DA UNIÃO. Publicado em: 24/03/2017 | Edição: 58 | Seção: 1 | Página: 119 Órgão: Ministério das Cidades/GABINETE DO MINISTRO. Disponível em <http://www.in.gov.br/materia/- 
asset_publisher/Kujrw0TZC2Mb/content/id/20122352/do1-2017-03-24-portaria-n-269-de-22-demarco-de-2017-20122235> Acesso em 20 fevereiro 2019.

MOREIRA, Camilla Fernandes (2013). O programa minha casa minha vida: uma análise dos impactos na cidade de Uberlândia - MG. 2013. 115 f. Dissertação (Mestrado em Ciências Humanas) Universidade Federal de Uberlândia, Uberlândia, 2013.

MOREIRA, Camilla Fernandes (2018). Explorando novas ferramentas jurídicas para promover o direito à moradia no contexto da globalização. in M. F. de Castro e H. L. P. Ferreira, orgs., Análise Jurídica Da Política Econômica: A Efetividade dos Direitos Na Economia Global. Curitiba: Editora CRV, 2018.

SECRETARIA DE ESTADO DE GESTÃO DO TERRITÓRIO E HABITAÇÃO (2007). Dinâmica Demográfica. Disponível em

$<$ http://www.segeth.df.gov.br/arquivos/pdot_revisao_2007/versao_cldf/demografia_df.pdf > Acesso em 10 maio 2017.

UNFPA (2018). Situação da População Mundial 2018 - O Poder de Escolha: Direitos reprodutivos e a transição demográfica. Disponível em < https://brazil.unfpa.org/pt-br/news/situacao-da-populacaomundial-2018> Acesso em 20 março 2019.

UNITED NATIONS (1991). Committee on Economical, Social and Cultural Rights. General Comment no 04. The right to adequate housing (Art.11 (1)). Geneva, 1991. Disponível em: < http://www.unhchr.ch/tbs/doc.nsf/(Symbol)/469f4d91a9378221c12563ed0053547e?Opendocumen $\mathrm{t}>$. Acesso em 02 maio 2017

UNITED NATIONS (2016). Onu-Habitat divulga rascunho de nova agenda urbana para o desenvolvimento sustentável. Disponível em <https://nacoesunidas.org/onu-habitat-divulgarascunho-de-nova-agenda-urbana-para-o-desenvolvimento-sustentavel/> Acesso em 20 março 2017.

VILLA, Simone B. ROTELLI, Nathália Barros Abate (2012). A qualidade da produção recente da habitação de interesse social na cidade de Uberlândia - MG, pós 2000. IV Congresso Brasileiro e III Congresso Ibero-Americano de Habitação Social: ciência e tecnologia "Inovação e Responsabilidade". 12 a 15 de novembro de 2012, Florianópolis.

WRI BRASIL (2016). O que a Nova Agenda Urbana propõe para as cidades. Disponível em $<$ http://wricidades.org/noticia/o-que-nova-agenda-urbana-prop\%C3\%B5e-para-cidades > Acesso em 20 março 2017.

Trabalho enviado em 30 de outubro de 2019 Aceito em 15 de maio de 2020 